\title{
A Novel Method for Navigational Risk Assessment in Wind Farm Waters Based on the Fuzzy Inference System
}

\author{
Peilin Lv $\mathbb{D}^{1}{ }^{1}$ Rong Zhen $\mathbb{D}^{1,2,3}$ and Zheping Shao $\mathbb{D}^{1}$ \\ ${ }^{1}$ Navigation College, Jimei University, Xiamen 361001, China \\ ${ }^{2}$ Hubei Key Laboratory of Inland Shipping Technology, Wuhan 430063, China \\ ${ }^{3}$ Intelligent Transportation Systems Research Center, Wuhan University of Technology, Wuhan 430063, China
}

Correspondence should be addressed to Rong Zhen; zrandsea@163.com

Received 6 August 2021; Accepted 18 October 2021; Published 29 November 2021

Academic Editor: Lazim Abdullah

Copyright (c) 2021 Peilin Lv et al. This is an open access article distributed under the Creative Commons Attribution License, which permits unrestricted use, distribution, and reproduction in any medium, provided the original work is properly cited.

\begin{abstract}
Offshore wind power is an effective way to solve the energy crisis problem and achieve sustainable economic development. Aiming at the problems that the navigational risk of ships in the waters of offshore wind farms is difficult to quantify due to complex factors, this paper proposes a method of navigational risk assessment in the waters of offshore wind farms based on a fuzzy inference system. Firstly, through the analysis of the factors affecting the navigation system of wind farm waters, it is found that the navigational risk is affected by natural factors and navigational environment factors. Then, the visibility, the number of traffic flows, the number of encounter areas, and the distance between the sailing route and the wind farm are extracted to evaluate the risk of natural factors and the risk of the sailing environment in the navigation system of the wind farm waters, respectively. Considering the mutual influence of the factors, the fuzzy inference rules of navigational risk influence are established according to the expert experience, and a method of navigational risk assessment based on the fuzzy inference system in offshore wind farm waters is developed. In order to verify the effectiveness of the proposed method, a comprehensive evaluation of the navigational risk of wind farm waters in Changle offshore sea of Fujian Province is carried out, and the evaluation results are consistent with the actual situation. The proposed method has important theoretical significance for the navigational safety supervision of offshore wind farm waters.
\end{abstract}

\section{Introduction}

With the continuous development of the economy and society, offshore wind farms for wind power generation are of great significance to alleviate the energy crisis and improve the environment. China is rich in offshore wind energy resources. By the end of 2019, China's grid-connected wind power has reached 210 million kilowatts, an increase of $10.9 \%$ over the previous year [1]. In the future, China's offshore wind farms will enter a period of accelerated development, but the construction of offshore wind farms is bound to have a certain impact on maritime traffic, especially the navigational safety of ships. Therefore, it is particularly important to evaluate and quantify the navigational risk of offshore wind farms, which has an essential theoretical significance for improving maritime traffic safety and optimizing shipping routes.
At present, the research on the navigational risk of ships in the waters of offshore wind farms mainly starts from the collision problem between the route and the wind farm and studies the collision avoidance method between ships and wind turbines. Xue et al. [2] studied the collision avoidance algorithm for ships based on software $A^{*}$. The key point is to find an optimal path, but the influence of wind, wave, and current on the safe navigation of ships is not considered in the modelling. $\mathrm{Pu}$ et al. [3] established a safety distance model and collision warning model between the ship and the wind farm and proposed a collision warning method based on an electronic fence to visually display the risk value of the ship collision with the wind turbine. Florian and Eike [4] proposed different anticollision measures for different situations by analyzing the risk of different types of ships hitting wind turbines. Many scholars analyze the 
relationship between waterways and wind farms and constantly improve the safe distance between ships and wind farms. Based on the collision probability model of ships and wind farms, Nie et al. [5] proposed a method to define the safe distance between wind farms and waterways based on the collision probability of ships and wind farms and obtained the conclusion that the safe distance between wind farms and routes is related to the average speed of ships, load tons, and the boundary length of wind farms. Wang et al. [6] built a calculation model for the safe distance between the offshore wind farms and the waterways based on the improved out-of-control drift model by comprehensively considering the factors such as ships, fans, wind, and flow and obtained the safe distance between different types of ships and wind turbines in the out-of-control state. Andrew and Edward [7] compared and analyzed the changes of ship traffic around five offshore wind farms before and after they were built and found that developers and regulators all regard 1 nautical mile ( $\mathrm{n}$ mile) as the safe passage distance for offshore wind farms.

In order to determine the locations of the wind farm or put forward suggestions for the safety of navigation, scholars conducted many studies of navigational risk assessments in offshore wind farm waters. Yun [8] proposed combining fuzzy comprehensive evaluation and the analytic hierarchy method to determine the best scheme of wind farm site selection. Wang [9] analyzed the navigational risk of wind farms from three aspects, nature, traffic, and wind farms, and proposed corresponding safety measures. Chen et al. [10] made a comparative analysis of various navigational risk assessment models and, based on the shortcomings of the NRA model, designed a navigational risk assessment framework that could provide a prediction of ship collision probability, and consequences, acceptability, and operability are yet to be verified. In the risk assessment, many scholars use the method of fuzzy inference. Ozturk et al. [11] presented three new parameters of distance, area, and speed and proposed a novel methodology based on machine learning and fuzzy inference to assess the risk of collision in the port approach; the proposed NCR assessment methodology gives accurate and reasonable risk degree in accordance with the navigation environment. Bukhari et al. [12] studied a dynamic method to calculate DCPA, TCPA, and azimuth directly by using the VTS radar input and proposed an intelligent real-time multiship collision risk assessment system based on the fuzzy inference system, which improved the process of manual risk assessment.

Based on the above analysis, most of the research studies on the navigational risk of ships in the waters of offshore wind farms are based on the site selection of wind farms and the collision avoidance between ships and wind turbines and other obstacles. They do not consider the collision avoidance between different traffic flows and ships nor carry out quantitative analysis on the overall navigational risk of ships in the waters of offshore wind farms. Compared with existing risk assessment methods such as AHP and fuzzy comprehensive evaluation [13], fuzzy inference system (FIS) can implement multiple complex factors as the input or single factor as the output of the nonlinear mapping relationship, and it has been widely used in many fields such as the study of ocean detector performance [14], solar irradiance prediction [15], and flood prediction [16]. The quantification of the navigational risk of wind farm waters is a complex problem under multiple factors. The main contributions of this paper are as follows:

(1) Through analyzing the factors affecting the navigational risk of wind farm waters, a hierarchical evaluation structure for navigational risk in offshore wind farm waters is built

(2) The multifactor navigational risk assessment in the hierarchical evaluation structure has been implemented using a fuzzy inference system, which can solve the problem that the influence factors of navigational risk in the waters of offshore wind farms are difficult to be quantified

Based on the analysis of factors affecting ship navigation in wind farm waters, a fuzzy inference model is established by extracting factors such as the number of traffic flows, the number of meeting areas, and the distance between the sailing route and the wind farm. The proposed navigational risk assessment method in offshore wind farm water based on the FIS can take the influencing factors into account directly and give a visual perception of the assessment results. It is an improvement compared with the existing research. Analyzing and quantifying the navigational risk of wind farm waters under the influence of multiple factors can provide certain theoretical support for improving the supervision of wind farm waters' navigation and optimizing the sea route.

\section{Influencing Factors of Navigational Risk in Offshore Wind Farm Waters}

The "risk" refers to a specific danger, and risk assessment is to determine the possibility and severity of the accident caused by the risk and make a comprehensive evaluation [17]. The risk in this paper refers to the probability that the ship sailing in the waters of the wind farm may cause losses due to various uncertain factors. Through the model constructed in this paper, this probability can be expressed with accurate numbers so that the ship pilots and water traffic management departments have a more intuitive perception of the risk degree of ship navigation.

To objectively and accurately evaluate the overall navigational risk of offshore wind farm waters, this paper selects several indicators from two aspects of natural conditions and navigational environment to build the navigational risk assessment model for ships in offshore wind farm waters, as shown in Figure 1.

2.1. Natural Conditions. The influence of natural conditions on ship navigation is mainly due to the influence of visibility, wind, flow, and other factors on navigational safety. 


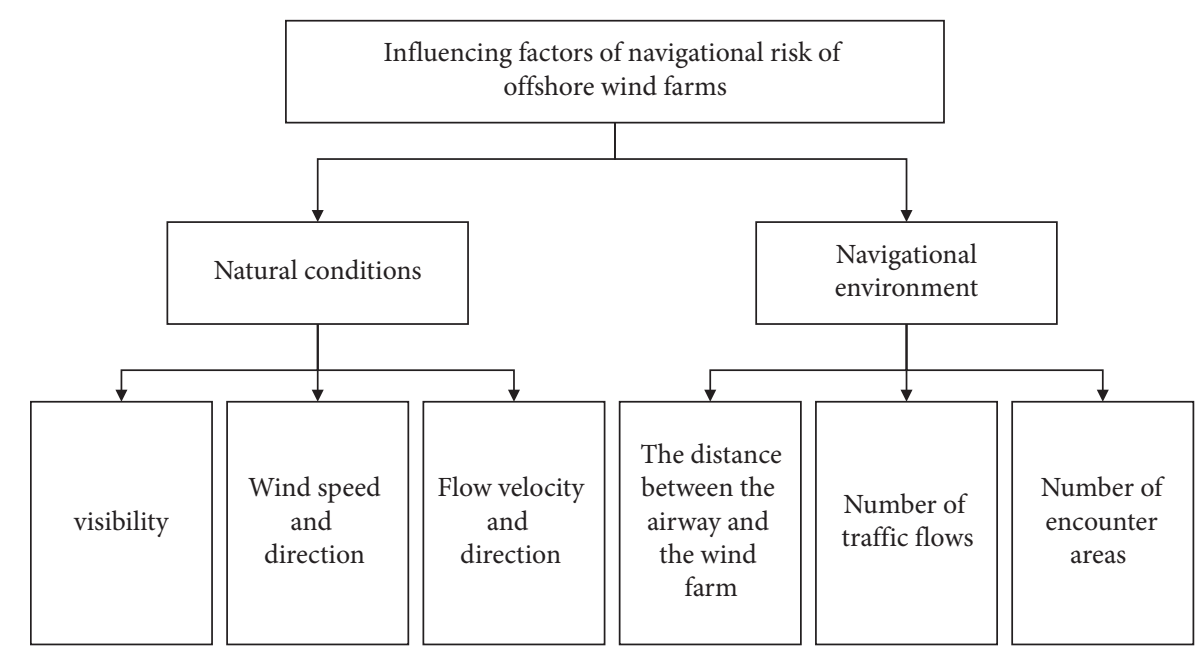

FIGURE 1: Hierarchical structure for offshore wind farm navigational waters' risk evaluation.

2.1.1. Visibility. Visibility is the maximum distance at which a person with normal vision can distinguish an object from the background. Too low visibility will greatly shorten the ship operator's response time and visual range, greatly increasing the risk of the ship operators. In 2018, there was more severe weather such as strong winds and fog in China. Under the condition of poor visibility, a total of 19 collision accidents occurred, and a total of 30 people were killed or missing, increasing $46.2 \%$ and $50.0 \%$, respectively, year on year [18]. It can be seen that good visibility is an essential factor to ensure the safety of normal navigation.

2.1.2. Wind Speed and Direction. The influence of wind on ships' navigation can be divided into two aspects: the speed of the wind and the direction of the wind. Ships' navigation is more or less affected by wind direction, especially in gale weather, which may cause ships to yaw, increase, or stall to a certain extent. In addition to the speed of the wind, the direction is also an essential factor that cannot be ignored. In particular, the lateral wind pressure will cause obvious lateral deviation of the ship and even the risk of rollover, which will seriously affect the normal driving of the driver. In 2018, 16 self-sinking accidents occurred under the influence of magnitude of seven storms and waves, with a total of 53 deaths and missing people, increasing by $23.3 \%$ and $48.3 \%$, respectively, year on year [18]. These data are enough to show that severe weather conditions such as strong winds and fog bring great threats to life safety and bring serious challenges to the maritime authorities' on-site supervision and emergency response.

2.1.3. Flow Velocity and Direction. Water flow is the most basic factor to ensure the normal sailing of ships. Many collision and grounding accidents are inseparable from the velocity and direction of water flow. When the traffic flow direction is in the same straight line as the ship's course, the current will only change the ship's speed and affect the difficulty of ship operation. When there is an angle between the direction of the flow and the course of the ship, the course of the ship will be affected, resulting in lateral drift, which brings unpredictable risk to the ship's navigation. Especially when sailing in narrow waterways or special waters, the flow velocity and direction of water are the factors that should be paid attention to ensure the safety of ship driving (the velocity in this paper refers to the ratio of the flow velocity and the ship speed).

\subsection{Navigational Environment}

2.2.1. Horizontal Distance between the Route and Wind Farms. When the ship sails into the waters of the wind farm, the whole wind farm as a navigational obstacle will pose a potential threat to the ship. The ship will inevitably be affected by uncertain factors such as wind, wave, and flow in the actual sailing process, which will lead to deviation from the scheduled course and change the scheduled speed. The most serious consequence is that the ship cannot sail autonomically and has lateral drift due to mechanical failure during this period. Therefore, the sailing route near the wind farm must keep a certain safe distance from the wind turbine, that is, the transverse drift distance in Figure 2, which provides enough time for emergency braking of out of control of the ship to avoid collision accidents.

2.2.2. Number of Traffic Flows. The concept of traffic flow was first put forward in the study of road traffic engineering and applied to marine traffic engineering, where it is the total number of ships sailing along a certain channel. The difference is that the road traffic flow focuses on improving traffic efficiency, while the maritime traffic flow focuses on improving traffic safety [19], which makes the number of traffic flows as an essential evaluation index for assessing the risk of ship operation in the navigational environment.

2.2.3. Number of Encounter Areas. When a ship travels in the sea, it will inevitably meet with other ships. To avoid danger, the ship must take a series of measures. This kind of 


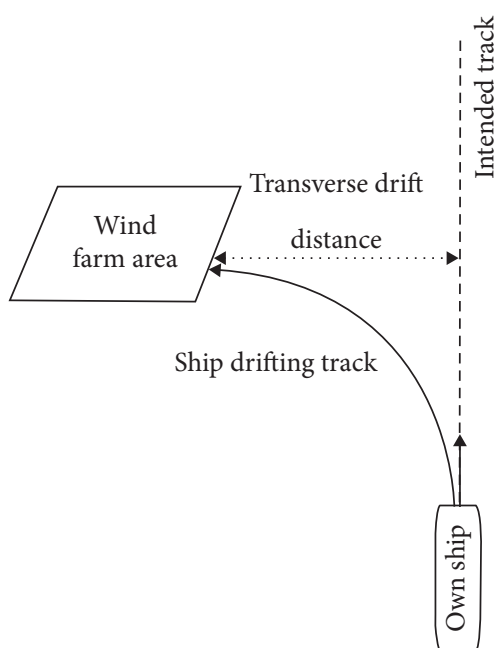

FIGURE 2: The position relationship between ship drifting with wind farms.

meeting of ships sailing on the sea and taking action is called "encounter." The "encounter" generally includes head on, crossing, and overtaking (this paper mainly studies the cases of head on and crossing situations), and the number of ship encounters and space-time distribution can be used to evaluate the marine traffic risk degree.

\section{Construction of the Risk Assessment Model for Offshore Wind Farm Waters}

Fuzzy theory was proposed by Professor Zedeh, an automatic control expert from the University of California at Berkeley in the United States, in 1965. At present, the fuzzy theory has been successfully applied in the fields of automatic control, data processing, decision analysis, and pattern recognition [20]. Fuzzy inference is essentially a computational process that maps a given input space to a specific output space utilizing logic. Fuzzy inference system (FIS) is a computational structure based on the concept of fuzzy set theory, fuzzy if-then rules, and fuzzy logic inference. From the perspective of function, the FIS is mainly composed of four parts: fuzzification, fuzzy rule base, fuzzy reasoning method, and defuzzification [21]. The specific structure is shown in Figure 3.

3.1. Fuzzification Method. There are four common fuzzification methods, and the appropriate method can be chosen to construct a membership function according to the actual situation [21].

(1) Fuzzy single-value method: let $x^{*}$ be the exact measured value and $\widetilde{A}^{*}$ be the fuzzy set converted by the fuzzy single-value method; then,

$$
\mu_{A}^{*}(x)= \begin{cases}1, & x=x^{*}, \\ 0, & x \neq x^{*} .\end{cases}
$$

(2) Triangle membership function method: let $x^{*}$ be a given exact quantity and $\widetilde{A}^{*}$ be the result of fuzzification; then, the triangle membership function can generally be written as

$$
\mu_{A}^{* *}(x)= \begin{cases}\left(\frac{x-a}{b-a}\right), & a \leq x \leq b, \\ \left(\frac{c-x}{c-b}\right), & b \leq x \leq c, \\ 0, & \text { others. }\end{cases}
$$

When the parameters $a=2, b=5$, and $c=8$, the membership function curve of the triangle distribution is shown in Figure 4.

(3) Gauss membership function method: let $x^{*}$ be a given exact quantity and $\widetilde{A}^{*}$ be the result of fuzzification; then, the Gaussian membership function can generally be written as follows:

$$
\mu_{A}^{*}(x)=e^{-\left(\left(x-x^{*}\right)^{2} / 2 \sigma^{2}\right)} .
$$

In this formula, the parameter $\sigma>0$ determines the width of the Gaussian function, and $x^{*}$ is the center point of the Gaussian function. The Gaussian curve when $x^{*}=2$ and $\sigma=5$ is shown in Figure 5.

(4) Trapezoidal membership function method: the shape of the membership function curve of the intermediate trapezoid distribution is determined by four parameters $a, b, c$, and $d$, and its expression is as follows:

$$
f(x ; a, b, c, d)= \begin{cases}0, & x \leq a, \\ \frac{x-a}{b-a}, & a \leq x \leq b \\ 1, & b \leq x \leq c \\ \frac{d-x}{d-c}, & c \leq x \leq d, \\ 0, & d \leq x .\end{cases}
$$

When the parameters $a=2, b=4, c=6$, and $d=8$, the membership function curve of the intermediate trapezoid distribution is shown in Figure 6.

3.2. Basic Form of Fuzzy Rules. The fuzzy rule base can be formulated according to the experience of experts. In this module, the extracted influencing factors can be combined to formulate risk degree rules for different combinations. On the deterministic domain $X$ and $Y$, the one-dimensional fuzzy rules are expressed as follows:

$$
\text { if } x \text { is } \widetilde{A} \text {, then } y \text { is } \widetilde{B} \text {. }
$$
follows:
The multidimensional fuzzy rules are expressed as lows: 


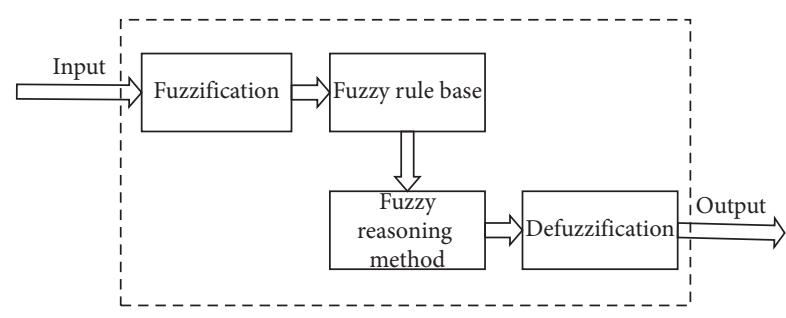

FIgURE 3: Fuzzy inference system structure diagram.

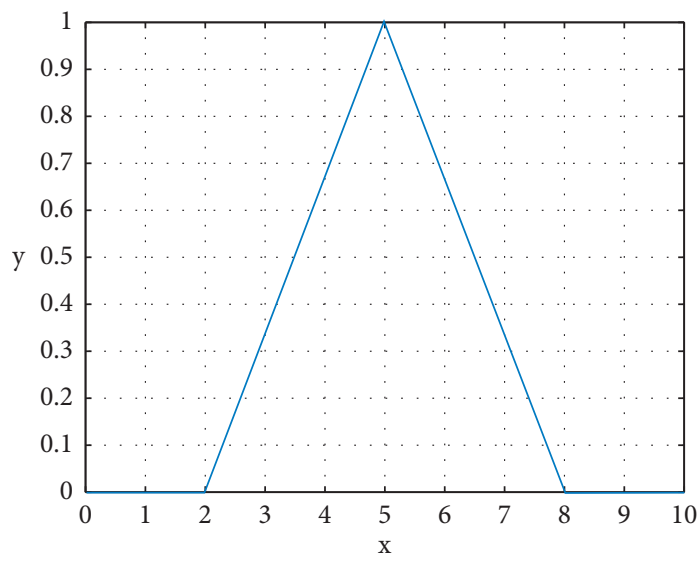

Figure 4: Triangle membership function method fuzzification process.

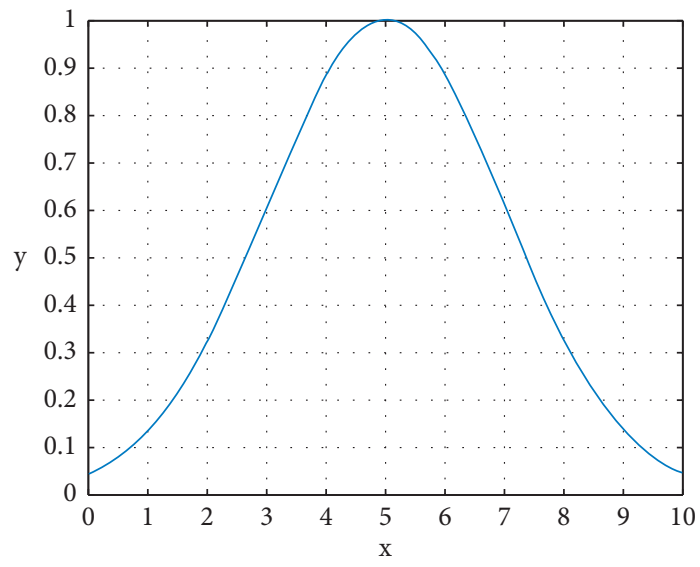

FIGURE 5: Gaussian membership function method.

$$
\text { if } x_{1} \text { is } \widetilde{A}_{1} \text { and } x_{2} \text { is } \widetilde{A}_{2} \text { and } \ldots \text { and } x_{n} \text { is } \widetilde{A}_{n} \text {, then } y \text { is } \widetilde{B} \text {. }
$$

Among them, $\widetilde{A}_{1}, \widetilde{A}_{2}, \ldots, \widetilde{A}_{n}$ are fuzzy sets on the domain $X$, and $B$ is a fuzzy set on $Y$.

3.3. Integrity and Monotonicity of Fuzzy Rules. The set of fuzzy rules is strict and rigorous work. an incomplete or not monotonous fuzzy rule base will make the evaluation results in deviation. Usually, it is hard to get a complete and monotonous fuzzy rule base only from the expert experience; existing research has many ways to address this question, such as the notion of a monotone fuzzy partition [22]. In this paper, genetic algorithm (GA) and approximate analogical reasoning schema (AARS) are combined to reduce the expert experience to be collected and meet the monotonicity:

Stage 1: GA is used to search for a small set of fuzzy rules gathered from expert experience

Stage 2: the remaining fuzzy rules are approximated by the similarity-based AARS [23]

3.4. Construction of the Risk Assessment Model. In order to quantitatively analyze the navigational risk of offshore wind farm waters, this paper extracts 6 influencing factors closely related to the overall navigational risk as input indexes and designs the model of navigational risk assessment in offshore wind farm waters based on the fuzzy inference system, as shown in Figures 7 and 8. After two layers of fuzzy inference, this model can obtain a quantitative navigational risk of ships in the waters of offshore wind farms.

Taking the second layer of fuzzy inference as an example [24], its fuzzy inference system is shown in Figure 9.

\section{Model Validation}

4.1. Introduction to Changle Offshore $C$ Wind Farm. In this paper, the area $C$ of the offshore wind farm waters in Changle, Fujian Province, is taken as an example to verify the validity of the model. The project is located in the eastern sea area of Changle of Fujian Province, the south bank of the Minjiang River estuary, and the waters on the northeast side of Pingtan Island. The site center is about $40 \mathrm{~km}$ away from the coastline of Changle, and the theoretical water depth is 41-47 $\mathrm{m}$. There are a number of recommended coastal routes in this place [25], and since sailing ships do not strictly follow the recommended routes, a number of customary routes are formed, resulting in a high navigational density of ships and relatively complex traffic conditions.

4.1.1. Natural Conditions. This sea area is rich in wind energy resources and affected by the "narrow tube effect" of the Taiwan Sea, the annual average wind speed can reach $8 \mathrm{~m} / \mathrm{s}$, and the annual average flow velocity is recommended to be 0.5 . According to statistics, the visibility in this sea area is good, and the visibility level can be set as 7 . Although the situation in which the wind direction and flow direction are abscissa is of great risk to the safe navigation of the ship, it can be simplified in the modelling process due to the less frequent occurrence.

4.1.2. Navigational Environment. To study the actual distribution of ship traffic flow in the offshore waters of Changle, the AIS thermal map is shown in Figure 10. It can be seen that there are a total of 11 customary routes near the wind farm, namely, the number of traffic flows is 11, and the number of encounter areas is 6 . The nearest route to this project is the connecting route of Songxia Port, which is $0.8 \mathrm{n}$ mile. 


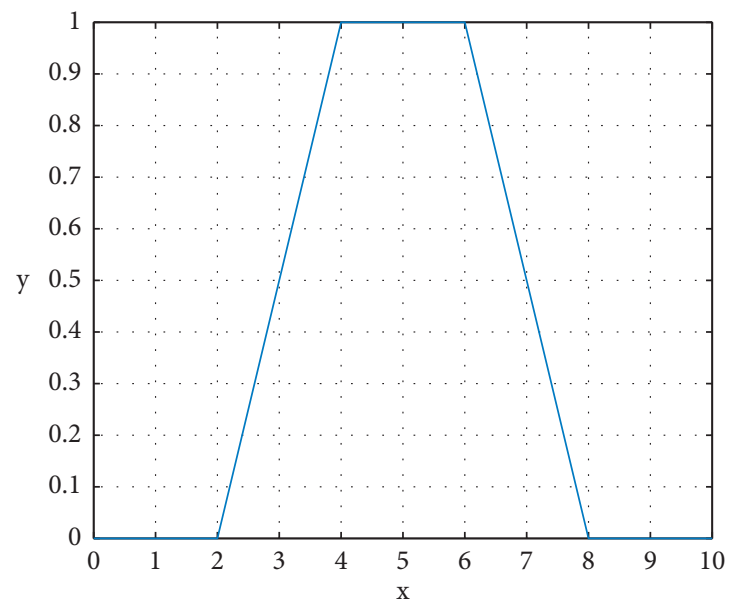

FIGURE 6: Trapezoidal Gaussian membership function.

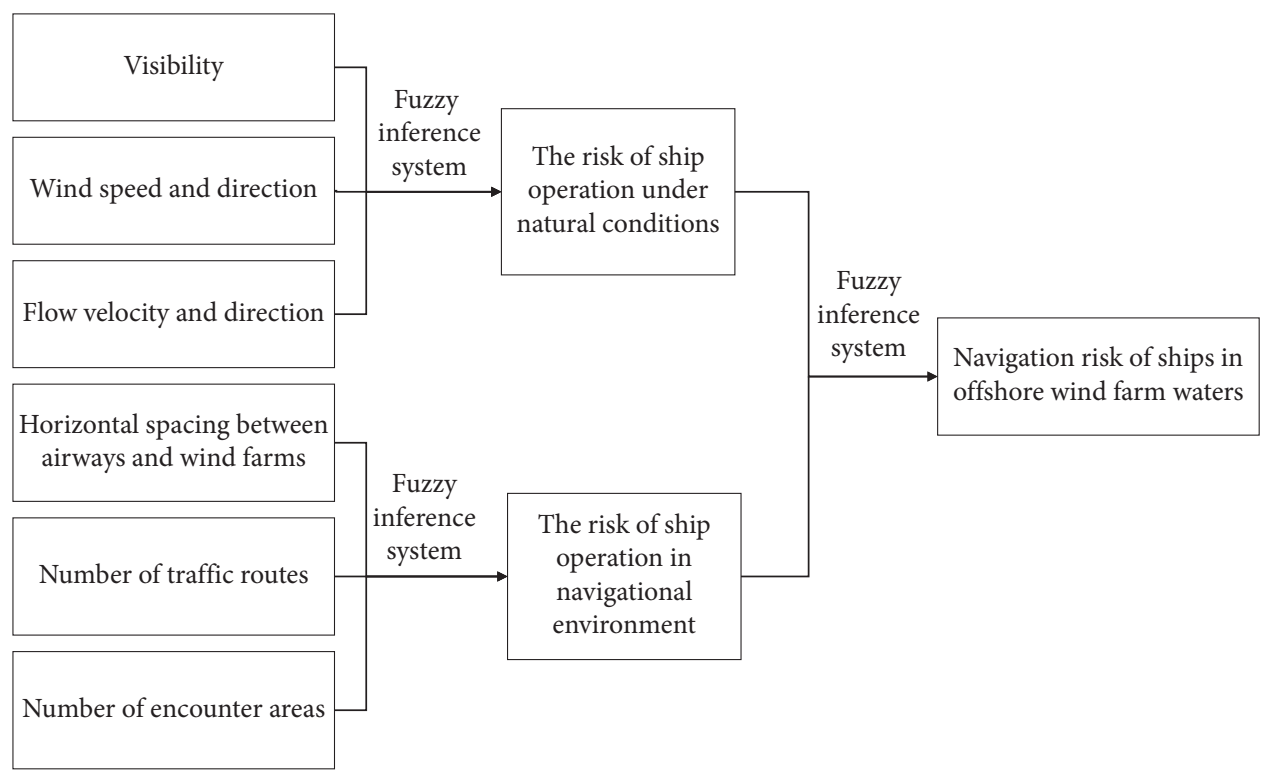

FIgURE 7: Assessment process of navigational risk in offshore wind farm waters.

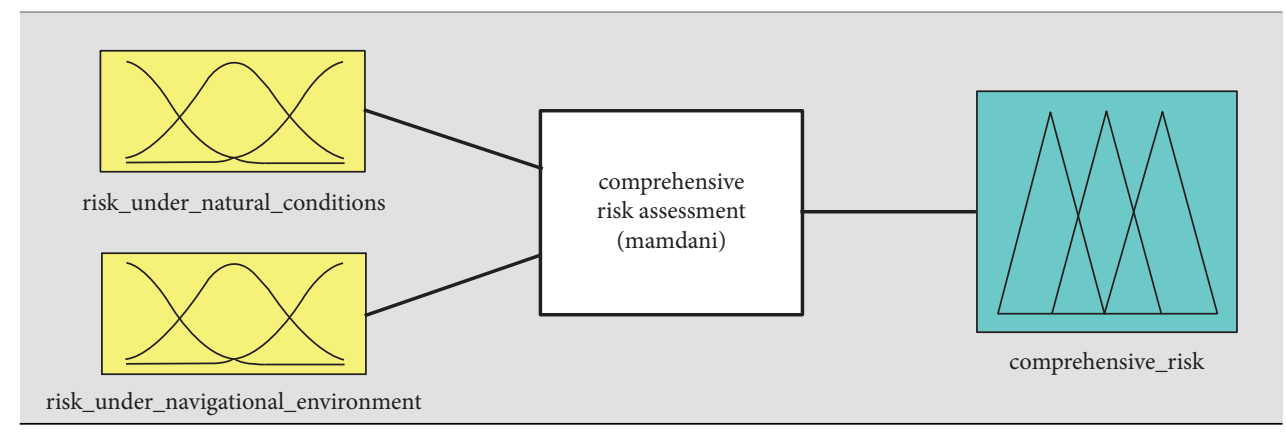

FIgURE 8: Navigational risk evaluation system for ships in the waters of offshore wind farms. 


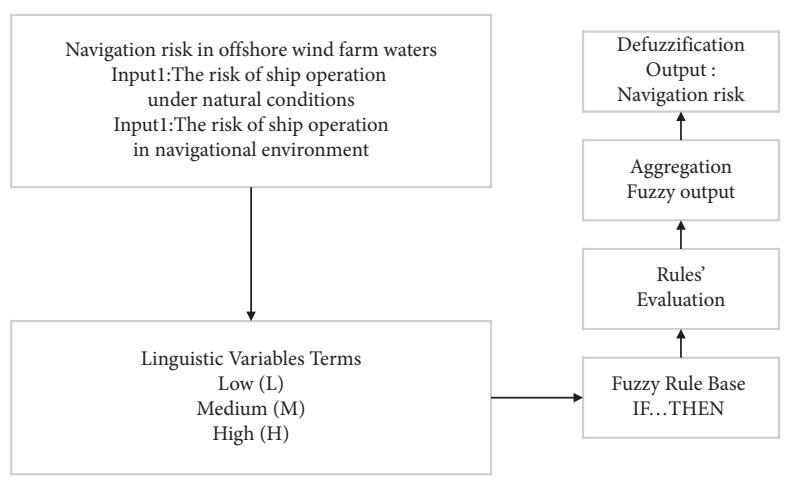

FIGURE 9: Fuzzy logic controller in navigational risk evaluation for ships in offshore wind farm waters.

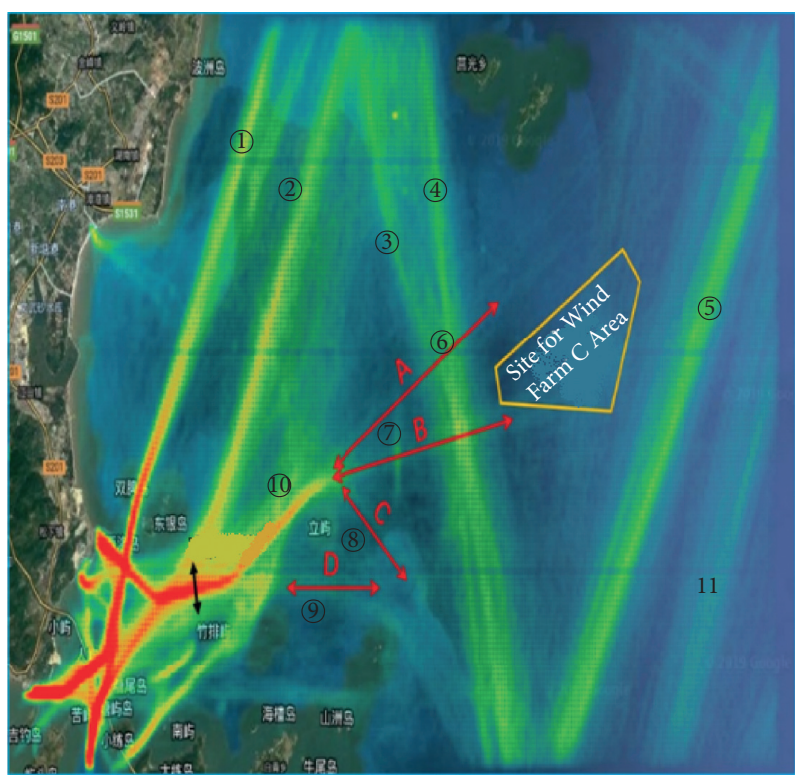

(a)

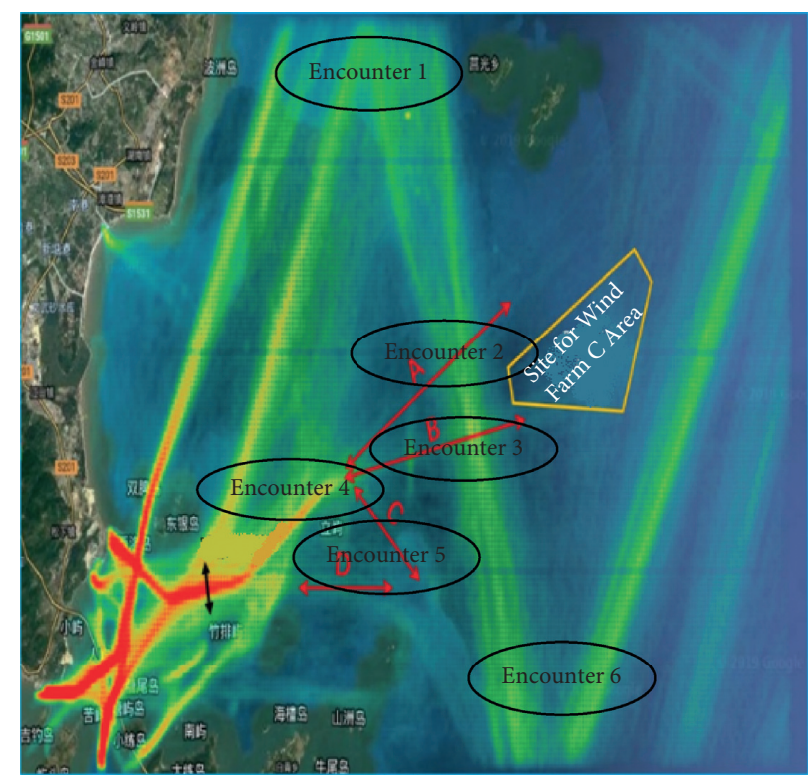

(b)

Figure 10: Thermal chart of ship trajectories in wind farm waters of area C. (a) Number of traffic routes. (b) Number of encounter areas.

\subsection{Model Validation Results}

4.2.1. The Risk of Ship Operation under Natural Conditions. According to the expert experience and actual influence, the fuzzy inference rule is established. It can be intuitive to see the relationship between various factors and ship operation risk under natural conditions, as shown in Figure 11. Then, the selected parameter values are brought into the risk model of sailing under natural conditions, and the exact value of the risk of sailing under natural conditions as shown in Figure 12 is " 3 ," which belongs to "medium risk."

4.2.2. The Risk of Ship Operation in the Navigational Environment. According to the impact analysis of the number of ship encounter areas, number of traffic flows, and horizontal space between sailing routes and wind farms, we conclude that when the number of encounter areas and traffic flows increases, the navigational risk of wind farms increases, while the horizontal space between sailing routes and wind farms increases, and the risk decreases. After consulting the ship officers and maritime experts, we build the membership function of each of two influencing factors, as shown in Figure 13.

When determining the safe distance between sailing routes and wind farms, scholars often refer to relevant international conventions, laws and regulations, industry regulations, or other research results. Considering comprehensively, the minimum safe distance between the sailing route and the wind farm is set as $2800 \mathrm{~m}$ [6] in this paper, and this is used as the critical value to define the risk under the influence of the distance between the route and the wind farm. The sailing conditions of Changle offshore sea are input into this fuzzy inference system, and the precise value of navigational risk under natural conditions is obtained, as shown in Figure 14; the value of risk is " 5 ," which belongs to "high risk."

4.2.3. Comprehensive Risk Assessment. The comprehensive FIS is established based on the comprehensive consideration of the influence of natural condition sailing risk and 


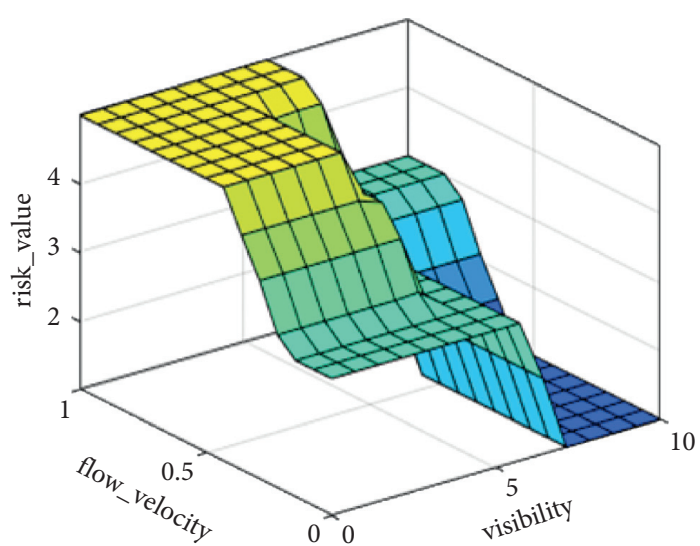

(a)

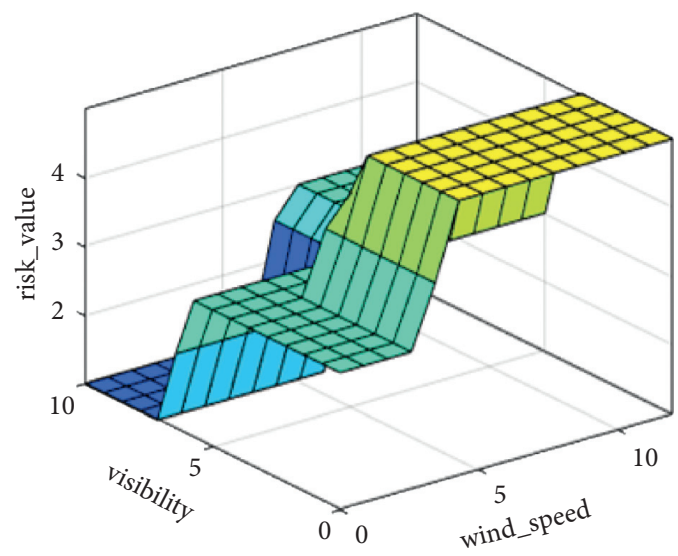

(b)

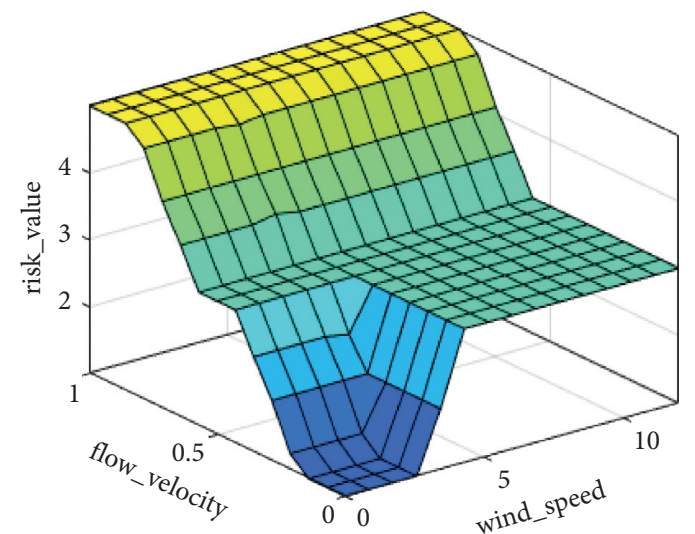

(c)

FIgURE 11: Natural conditions' risk membership function surface. (a) The relation surface between visibilities. (b) The relation surface between wind speed and visibility. (c) The relation surface between wind speed and flow visibility.

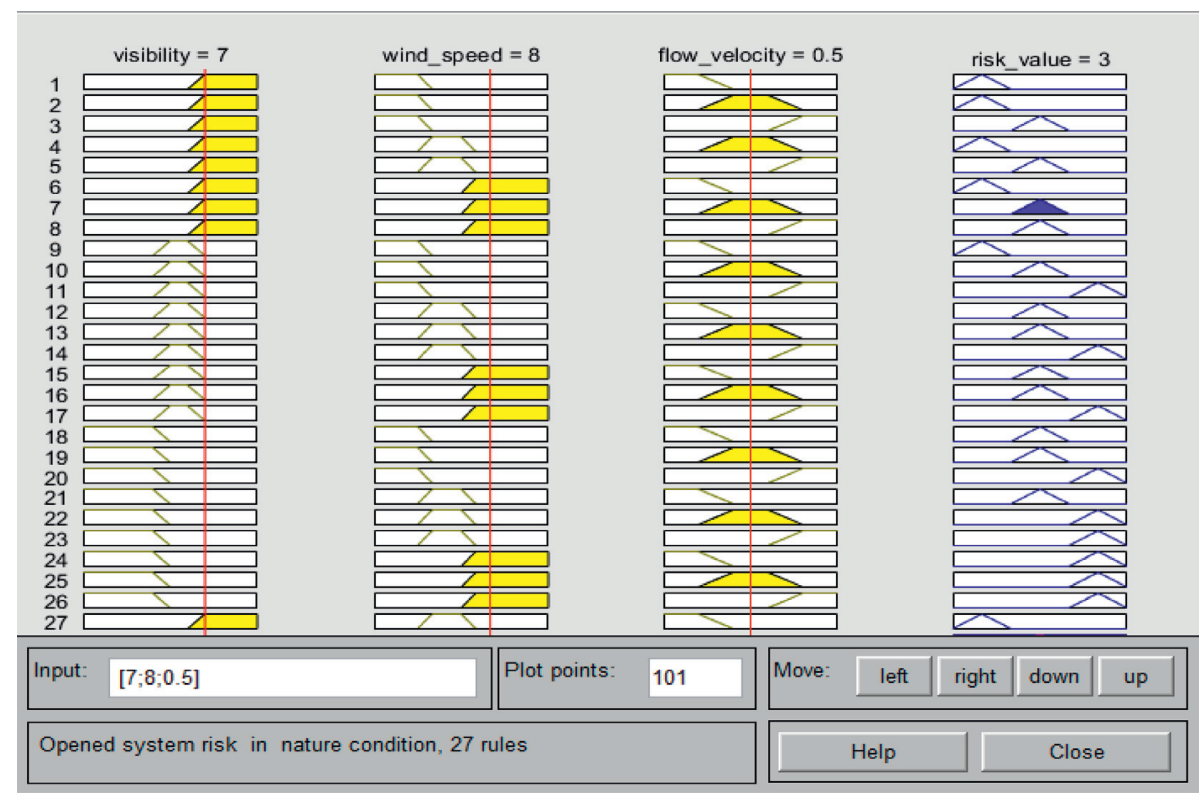

FIGURE 12: Navigation risk under natural conditions. 


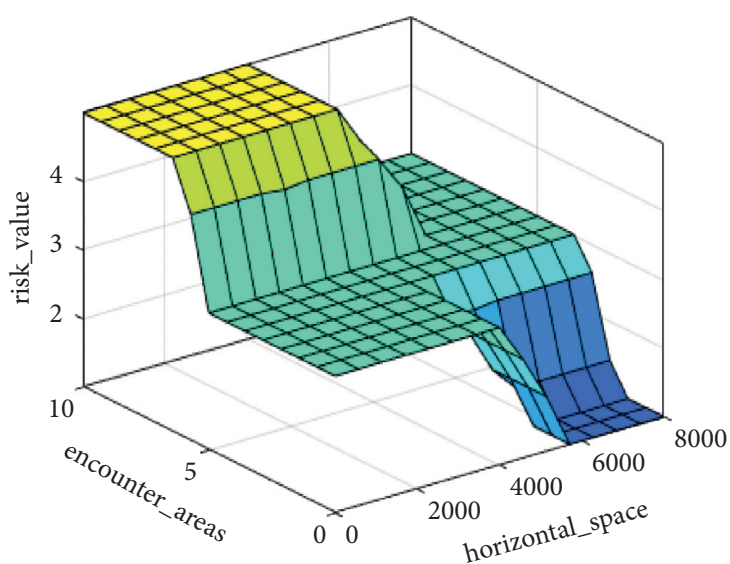

(a)

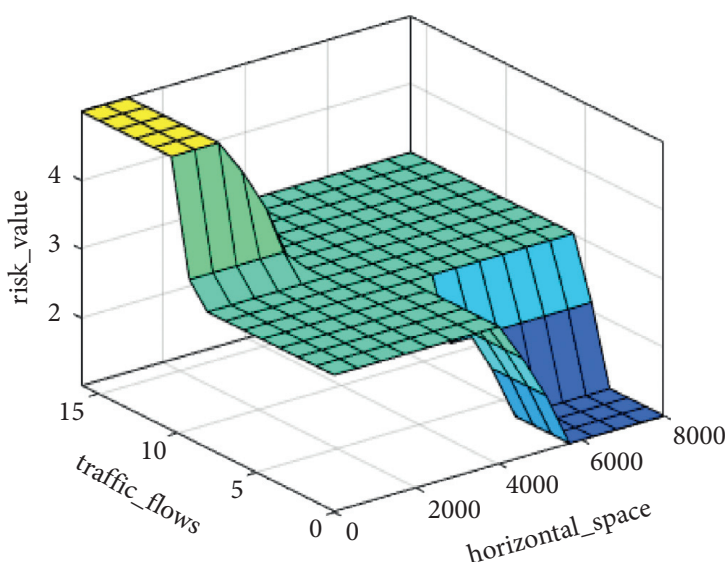

(b)

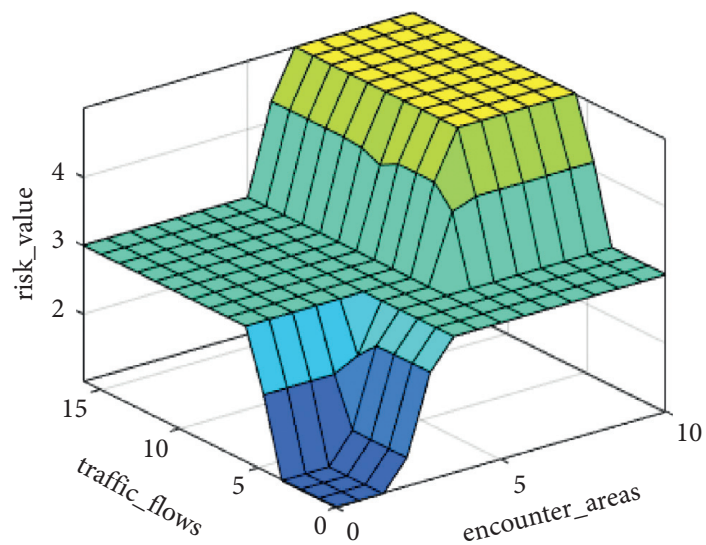

(c)

FiguRE 13: Navigational environment risk membership function surface. (a) The relation surface between the horizontal space and encounter area. (b) The relation surface between the horizontal space and traffic flow. (c) The relation surface between encounter area and traffic flow.

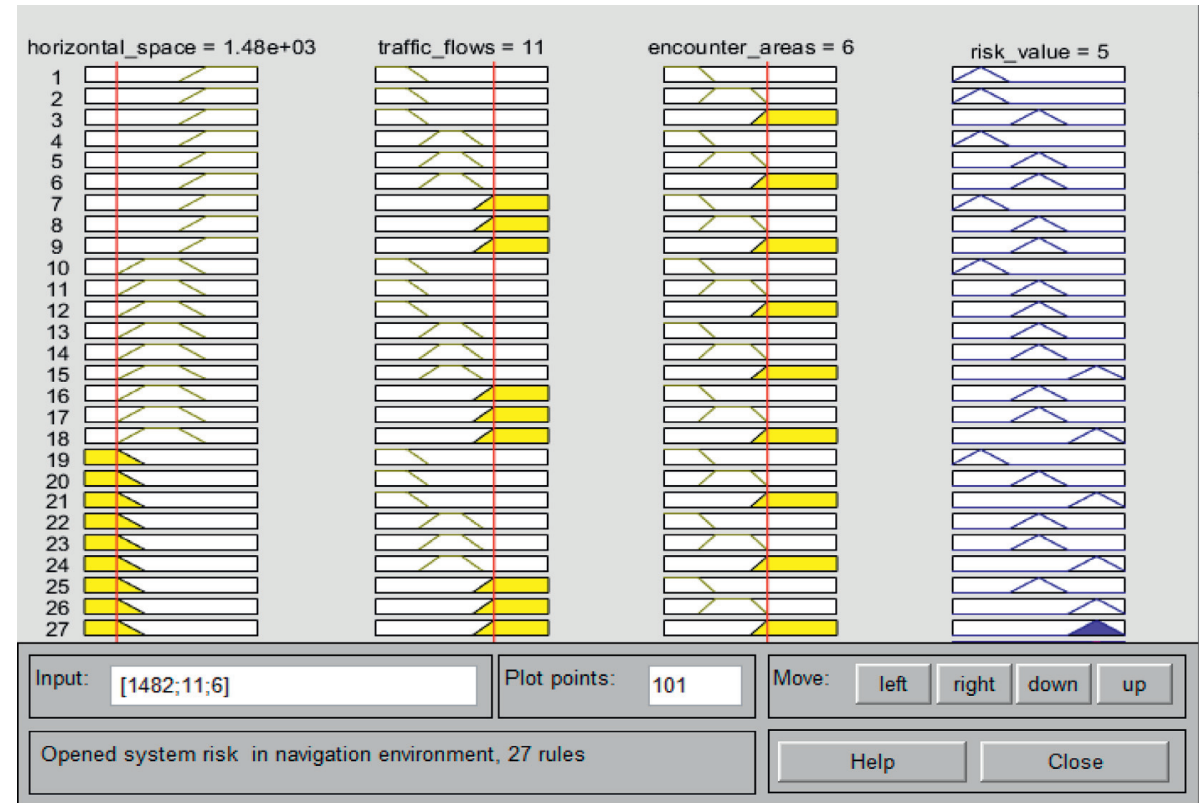

FIGURE 14: Navigational risk under the navigational environment. 


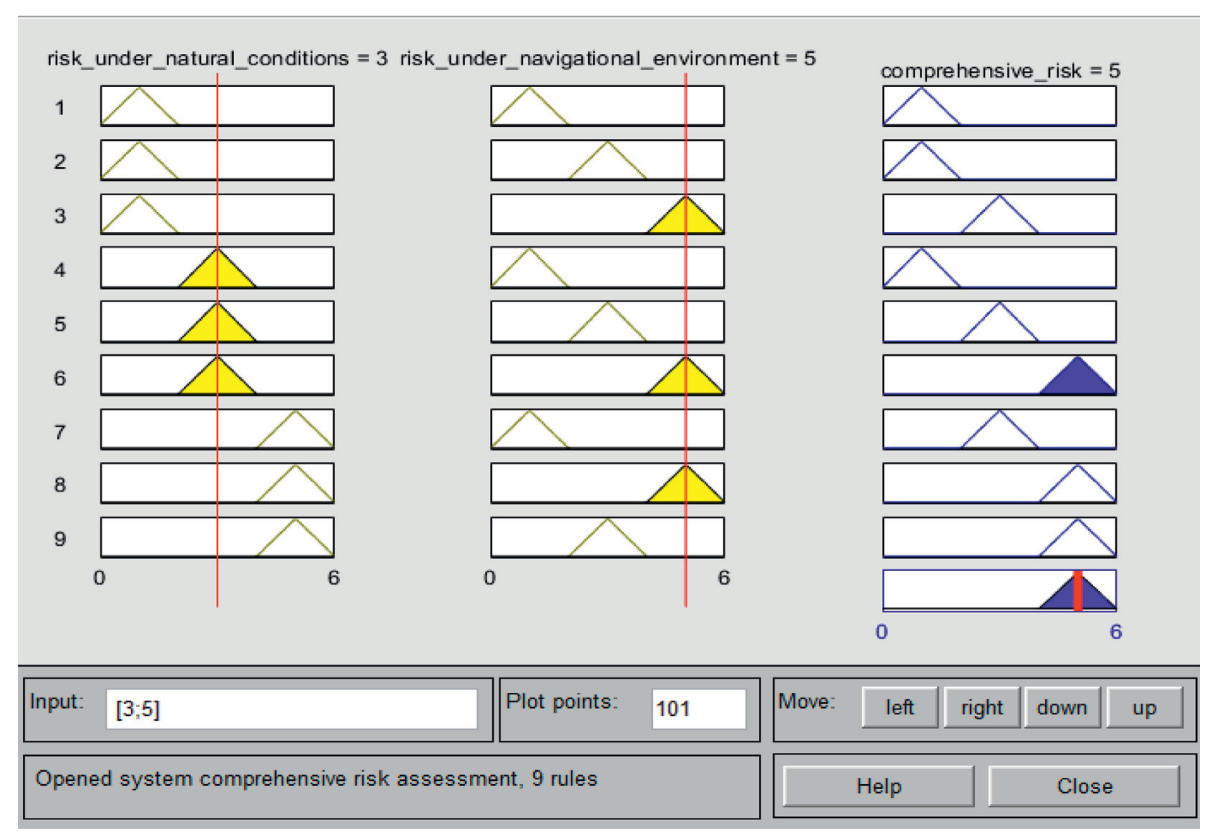

FIGURE 15: Original comprehensive navigational risk assessment.

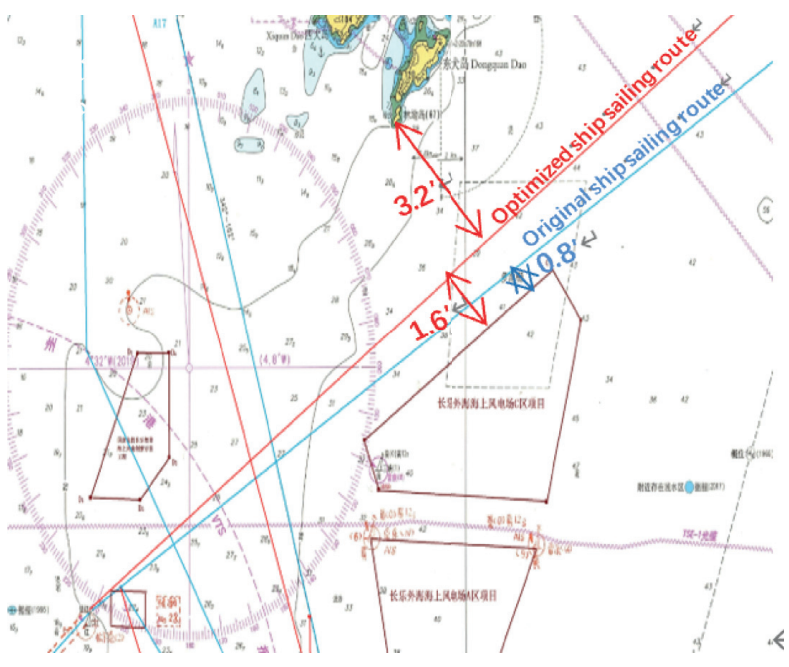

(a)

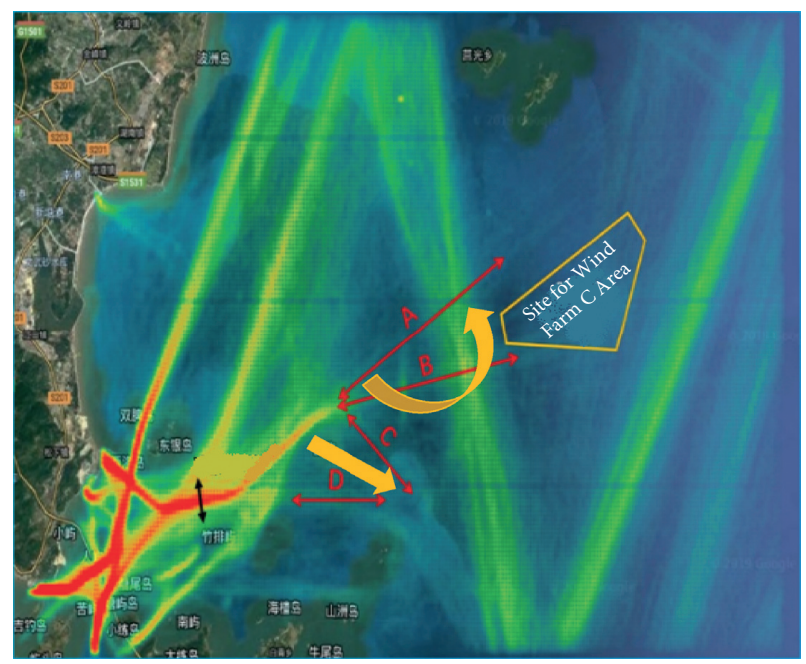

(b)

Figure 16: Optimized route distribution diagram. (a) Distance optimization between the airway and the wind farm. (b) Traffic flow number optimization.

navigational environment sailing risk on the overall navigational risk, and the obtained natural condition sailing risk " 3 " and navigational environment sailing risk " 5 " are input into the comprehensive fuzzy inference system, and the navigational risk of ships in the whole Changle offshore wind farm area of Fujian is finally obtained as " 5 ." These are "highrisk" navigational waters, as shown in Figure 15.

4.3. Route Optimization. The construction of the project of Changle Offshore Wind Farm in zone $C$ has affected the navigation of ships in the area, especially the routes from Songxia Port to the main channel, and increased the navigational risk of ships. It can be intuitively seen from the above model verification results that the navigational risk level of the waters near the project is as high as " 5 ," so it is necessary to optimize the nearby route.

Through investigation and analysis, as shown in Figure 16, the distance between Matsushita Port area's connecting route and the wind farm can be adjusted to $1.6 \mathrm{n}$ miles. At the same time, airway $B$ can be merged into airway $A$, and airways $C$ and $D$ can be integrated into a traffic flow.

After the sailing route optimization, the number of traffic flows is reduced to 9, the number of encounter areas is reduced to 4 , and the distance between the airways and the wind farm is increased to $1.6 \mathrm{n}$ miles. The optimized data are 


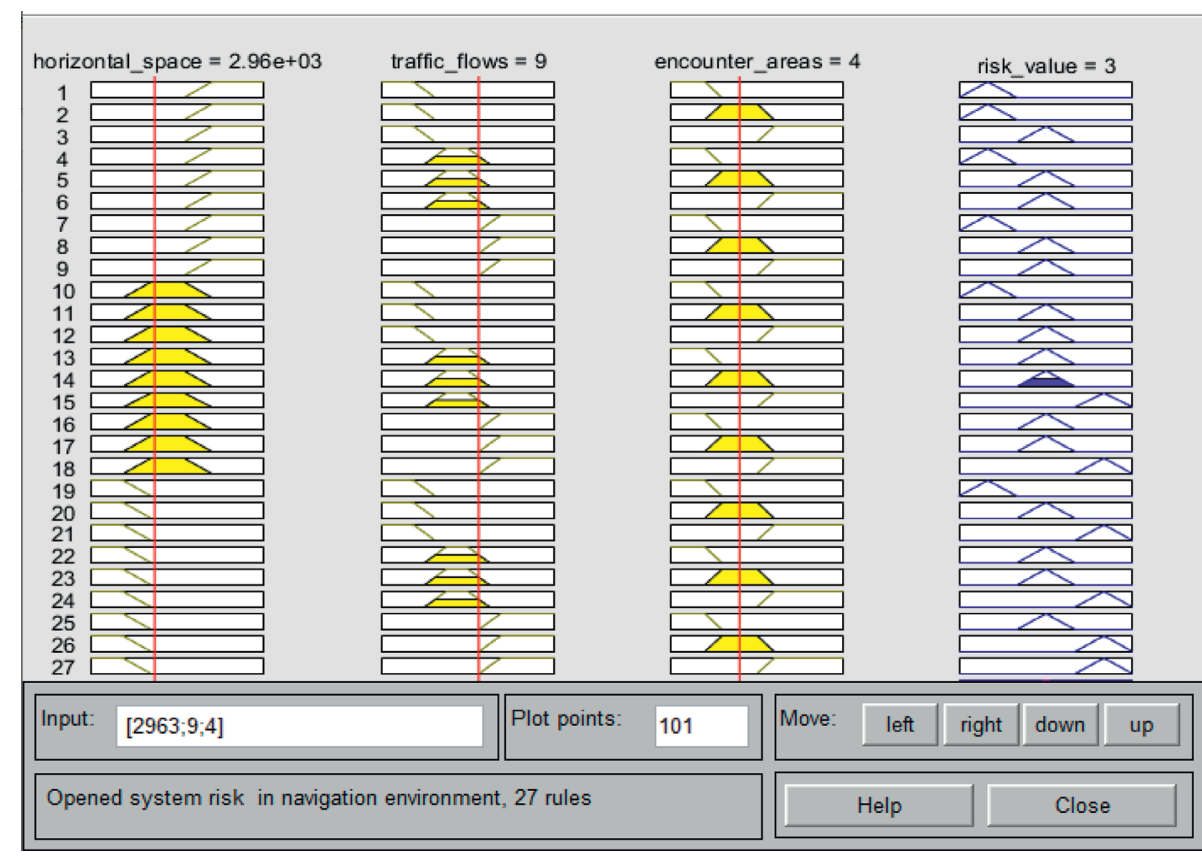

FIGURE 17: Navigational environment risk after sailing route optimization.

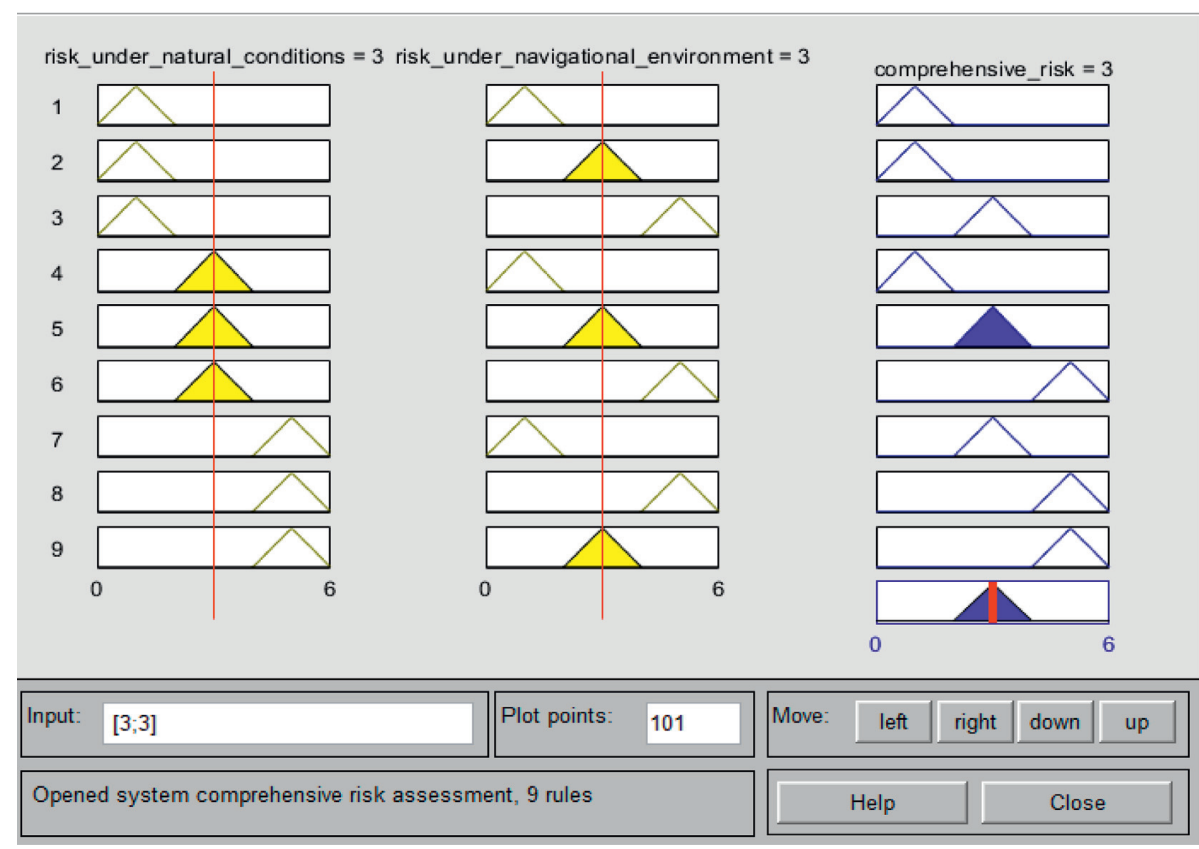

FIGURE 18: Comprehensive navigational risk assessment after route optimization.

resubstituted into the navigational risk model and the comprehensive risk assessment model, as shown in Figures 17 and 18; we find that the navigational risk of the ships in this area is reduced to " 3 ," belonging to "medium risk" navigational risk.

The above analysis shows that the evaluation method studied in this paper is feasible, and the fuzzy inference system can effectively calculate the navigational risk in the waters of offshore wind farms, and the calculated results meet the actual situation, thus verifying the rationality of the model.

\section{Discussion}

In order to verify the reliability of the model in this paper, other risk assessment methods, such as analytic hierarchy process (AHP) and fuzzy comprehensive evaluation, have been compared; we also implemented a comparative case study of the AHP in the same wind farm waters, and the results are shown in Figure 19. The blue decagon in the figure represents the risk value of each factor before optimization, and each corner represents the risk value of a factor. Similarly, red represents the risk value after optimization. 


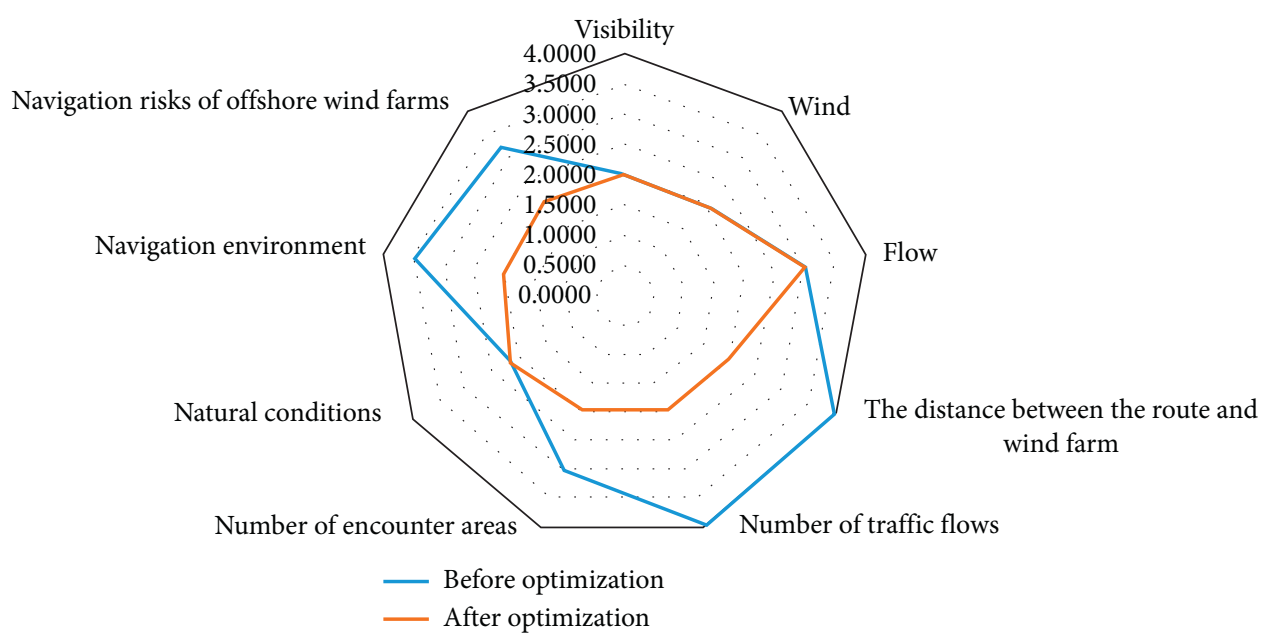

FIgURE 19: Evaluation of each risk index before and after route optimization using AHP and fuzzy comprehensive evaluation.

The research results showed that the AHP-based method has consistent results with the method proposed in this paper, and the evaluation value of each index obtained by the AHP and fuzzy comprehensive evaluation method has been improved before and after optimization. However, the AHPbased method depends on the subjective factors of people, the evaluation value obtained is easy to change, the calculation is complicated, and every scene needs to be recalculated. After the comparison, the FIS-based method proposed in this paper is more reliable and convenient for practical use.

\section{Conclusions}

In order to quantitatively evaluate the impact of the construction of offshore wind farms on the maritime navigational risk, this paper proposes a method of navigational risk assessment for offshore wind farms based on the fuzzy inference system. We analyze the influence of natural condition factors and navigational environment factors on the navigational environment. By extracting visibility, the number of traffic flows, the number of meeting areas, and distance between sailing routes and wind farms, the risk of natural condition and navigational environment operation in the navigational system of ships in the wind farm area is, respectively, evaluated. Considering the mutual influence of several factors, combined with the expert experience and established fuzzy inference rules, then finally the framework of navigational risk assessment based on the fuzzy inference system in offshore wind farm waters is formed. Taking the actual scene of wind farm water area $C$ of the Changle coast of Fujian Province as an example, the proposed method is verified. The experimental results showed that the proposed method can quantitatively evaluate the navigational risk in the wind farm waters, which provides a theoretical basis for the optimization of sea routes and the supervision of ships' navigational risk. Compared with the existing research, the proposed navigational risk assessment method in offshore wind farm water based on the FIS can take all the influencing factors into account directly and give a visual perception of the assessment results. In this paper, the natural conditions and navigational environment and their subfactors are considered as the main factors affecting the risk of wind farm waters for fuzzy inference system modelling. Actually, the factors of human and machine can raise the accident of ship's sailing in the waters of offshore wind farms, such as misjudgement, miscommunication between officers on the ship, and malfunction of navigation equipment of ships; we will take the above factors into account in the following research in the future.

\section{Data Availability}

The data presented in this study are available from the corresponding author upon request.

\section{Conflicts of Interest}

The authors declare that there are no conflicts of interest.

\section{Acknowledgments}

This work was supported by the National Natural Science Foundation of China (Grant no. 52001134), Science and Technology Innovation Special Zone Project of Science and Technology Department of Central Military Commission (Grant no. KL12004), Natural Science Foundation of Fujian Province (Grant no. 2020J01661), Youth Science and Technology Project of Education Department of Fujian Province (Grant no. JAT190293), Doctoral Research Startup Fund of Jimei University (Grant no. ZQ2019014), Hubei Provincial Key Laboratory of Inland River Navigation Technology (Grant no. NHHY2020001), and Open Foundation of Jimei University (Grant no. HHXY2020005).

\section{References}

[1] Keep Turning Green! in 2019, China's Grid-Connected Wind Power Photoelectricity Increased Substantially, 2021, http:// www.nea.gov.cn/2020-02/05/c_138757642.htm. 
[2] S. F. Xue, L. Xie, S. W. Wang, W. T. Xia, and Z. Bao, "Offshore wind farm area of ship collision avoidance pathfinding algorithm A *," Navigation of China, vol. 41, no. 2, pp. 21-25, 2018.

[3] Y. Q. Pu, C. S. Wu, Q. Y. Zhong, and J. Wang, "Ships and offshore wind farm collision risk and early warning method study," China Water Transport, vol. 12, no. 675, pp. 34-37, 2020.

[4] B. Florian and L. Eike, "Collisions of ships and offshore wind turbines: calculation and risk evaluation," in Proceedings of the ASME 25th International Conference on Offshore Mechanics and Arctic Engineering, pp. 663-670, Hamburg, Germany, June 2006.

[5] Y. Y. Nie, K. Z. Liu, X. Yang, S. Z. Chen, and J. Ma, "The safe distance between the offshore wind farm and the airway," Navigation of China, vol. 42, no. 4, pp. 12-17, 2019.

[6] G. P. Wang, Q. Y. Zhong, and C. B. Zhu, "Study on the determination of safe distance between offshore wind farm and air route," China Water Transport, vol. 12, no. 4, pp. 35-38, 2020.

[7] R. Andrew and R. Edward, Assessing the Impacts to Vessel Traffic from Offshore Wind Farms in the Thames Estuary, Scientific Journals of the Maritime University of Szczecin, Szczecin, Poland, 2015.

[8] L. P. Yun, Wind Farm Location Optimization of Fuzzy Comprehensive Evaluation Research, North China Electric Power University, Beijing, China, 2008.

[9] F. Wang, "Navigation safety analysis of offshore wind farm," Word Shipping, vol. 42, no. 1, pp. 32-34, 2019.

[10] L. P. Chen, J. H. Chen, Z. H. Wu, P. Zhou, P. Peng, and H. C. Zhang, "Advances in risk assessment of offshore wind power navigation," Navigation of China, vol. 43, no. 3, pp. 52-56, 2020.

[11] U. Ozturk, S. I. Birbil, and K. Cicek, "Evaluating navigational risk of port approach manoeuvrings with expert assessments and machine learning," Ocean Engineering, vol. 192, 2019.

[12] A. C. Bukhari, I. Tusseyeva, B.-G. Lee, and Y.-G. Kim, "An intelligent real-time multi-vessel collision risk assessment system from VTS view point based on fuzzy inference system," Expert Systems with Applications, vol. 40, no. 4, pp. 1220-1230, 2013.

[13] Y. L. Bi, Study on Fuzzy Comprehensive Evaluation of Ship Navigation Environment Safety in Binzhou Port, Dalian Maritime University, Dalian, China, 2020.

[14] M. Y. Zhu, D. K. Chen, J. L. Wang, and Y. Sun, "Analysis of oceanaut operating performance using an integrated Bayesian network aided by the fuzzy logic theory," International Journal of Industrial Ergonomics, vol. 83, no. 1, 2021.

[15] X. Zhao, L. P. Xie, H. K. Wei, H. Wang, and K. Zhang, "Fuzzy inference systems based on multi-type features fusion for intra-hour solar irradiance forecasts," Sustainable Energy Technologies and Assessments, vol. 45, Article ID 101061, 2021.

[16] T. Ruhhee and Q. Abdul, "Modelling hybrid and backpropagation adaptive neuro-fuzzy inference systems for flood forecasting," Natural Hazards, vol. 108, no. 1, pp. 519-566, 2021.

[17] S. Yin, "Safety and risk related concept analysis," Quality and Reliability, vol. 3, pp. 50-52, 2011.

[18] Inventory and Analysis of Water Traffic Accidents in 2018, 2021, https://www.sohu.com/a/300732728_99897235.

[19] Z. L. Wu and J. Zhu, Marine Traffic Engineering, Shanghai Maritime University Press, Daliang, China, 2nd edition, 2004.

[20] L. A. Zadeh, "Fuzzy sets," Information and Control, vol. 8, no. 3, pp. 338-353, 1965.
[21] J. Xie and C. Liu, Fuzzy Mathematics Method and Application, Huazhong University of Science and Technology Press, Wuhan, China, 4th edition, 2000.

[22] Y. W. Kerk, K. M. Tay, and C. P. Lim, "Monotone interval fuzzy inference systems," IEEE Transactions on Fuzzy Systems, vol. 27, no. 11, pp. 2255-2264, 2019.

[23] T. L. Jee, K. M. Tay, and C. P. Lim, "A new two-stage fuzzy inference system-based approach to prioritize failures in failure mode and effect analysis," IEEE Transactions on Reliability, vol. 64, no. 3, pp. 869-877, 2015.

[24] E. N. Madi and A. O. M. Tap, "On fuzzy financial planning model," in Proceedings of the 2010 2nd IEEE International Conference on Information Management and Engineering, pp. 254-258, Xi'an, China, August 2010.

[25] China Maritime Safety Administration, China Coastal Navigation Guide East China Sea, China Communications Press, Beijing, China, 2019. 